\title{
COMMENTARY
}

\section{Venous congestion: are we adding insult to kidney injury in sepsis?}

\author{
Rajkumar Rajendram ${ }^{1}$ and John R Prowle $2^{2^{*}}$ \\ See related research by Legrand et al., http://ccforum.com/content/17/6/R278
}

\begin{abstract}
In critical illness, septic shock is a contributing factor in nearly half of all cases of acute kidney injury (AKI).

Traditional approaches to prevention of organ dysfunction in early sepsis have focused on prevention of hypoperfusion by optimisation of systemic haemodynamics, primarily by fluid resuscitation. Fluid administration to a target central venous pressure (CVP) of 8 to $12 \mathrm{mmHg}$ (12 to $15 \mathrm{mmHg}$ in mechanically ventilated patients) is currently recommended for the early resuscitation of septic shock. However, in the previous issue of Critical Care, Legrand and colleagues report that higher CVP in the first 24 hours of ICU admission with septic shock was associated with increased risk for development or persistence of AKI over the next 5 days. This study highlights a potential association between venous congestion and the development of septic AKI, suggesting that CVP-targeted fluid resuscitation in septic shock might not be beneficial for renal function.
\end{abstract}

Septic shock is consistently the most common causative factor identified for acute kidney injury (AKI) in critical illness, and has been associated with nearly $50 \%$ of cases internationally. Despite advances in our understanding of the pathophysiology of septic AKI, treatment aimed at reversing or preventing septic AKI remains primarily based on supportive haemodynamic management. In the previous issue of Critical Care, Legrand and colleagues examine the association between haemodynamic targets of resuscitation (cardiac output, mean or diastolic blood pressure, central venous pressure (CVP) and central venous oxygen saturation) and development or persistence

\footnotetext{
* Correspondence: John.Prowle@bartshealth.nhs.uk

${ }^{2}$ Adult Critical Care Unit, The Royal London Hospital, Barts Health NHS Trust, Whitechapel Road, London E1 1BB, UK

Full list of author information is available at the end of the article
}

of AKI in a single centre study of patients with septic shock admitted to a surgical ICU [1].

The authors found that only higher CVP and low diastolic blood pressure were associated with increased risk of development of new AKI, or persistence of renal dysfunction present at ICU admission. In these patients new or persistent AKI was significantly associated with increased risk of death in hospital. Importantly, the association between CVP and AKI remained when potentially confounding effects of positive fluid balance and higher positive end-expiratory pressure were accounted for in a multivariable analysis. So, a $5 \mathrm{mmHg}$ increase in CVP predicted 2.7-fold odds of new or persistent AKI. Furthermore, when the association between different levels of mean CVP and AKI was examined in a nonparametric logistic regression, there was a trend for higher CVP to be associated with worse renal outcome for all levels of CVP from $4 \mathrm{mmHg}$ upward, so that a CVP of $15 \mathrm{mmHg}$ was associated with an approximately $80 \%$ risk of new or persistent AKI, compared to approximately $30 \%$ at a CVP of $6 \mathrm{mmHg}$.

These findings are important because current surviving sepsis campaign guidelines recommend fluid resuscitation of patients with sepsis-induced tissue hypoperfusion to target a CVP of 8 to $12 \mathrm{mmHg}$ (or 12 to $15 \mathrm{mmHg}$ in mechanically ventilated patients) within 6 hours of presentation [2]. In patients with sepsisinduced hypotension the rationale for CVP targeted fluid resuscitation is to ensure 'adequate' cardiac preload and hence maintain cardiac output and organ perfusion. However, absolute levels or changes in CVP poorly predict cardiovascular response as sepsis-induced hypotension is multi-factorial, related to changes in myocardial performance, vascular tone, regional blood flow distribution, venous reservoir capacity and capillary permeability. In contrast, elevated CVP will cause a direct and predictable increase of renal venous pressure that, experimentally, has been associated with elevated renal interstitial and intra-tubular pressure [3]. Resultant 
renal venous congestion can reduce renal blood flow (lower trans-renal pressure gradient) and decrease the pressure gradient for ultrafiltration (higher intra-tubular pressure). In septic shock, fluid therapy will only effectively reverse any contribution of hypovolaemia to systemic hypotension. Aggressive fluid resuscitation beyond reversal of hypovolaemia to arbitrary CVP targets could result in increased venous congestion without substantial benefit to forward renal perfusion, thus predisposing to renal dysfunction.

The association between elevated CVP and renal dysfunction has been made previously in the setting of chronic cardiac failure [4]. Now Legrand and colleagues have provided evidence that such an association is observed in septic shock and its treatment. Their findings are also in accord with secondary analysis of the Vasopressin in Septic Shock Trial [5], which reported that a more positive fluid balance and elevated CVP were associated with increased mortality in patients with septic shock even when accounting for differences in baseline illness severity and demographics.

Although these observational findings are hypothesisgenerating rather than confirmatory, they add weight to the literature suggesting the adverse effects of fluid overload in critical illness and AKI in particular [6], effects that may be mediated in part by venous congestion causing impaired organ function. It is now important to determine whether uncritical pursuit of CVP targets such as those advocated by the surviving sepsis campaign might, in some patients, add insult to sepsis-induced organ injury. Prospective data are required to evaluate the true contribution of raised venous pressure to renal and other organ dysfunction and to determine better endpoints for fluid resuscitation in sepsis.

\section{Abbreviations}

AKI: Acute kidney injury; CVP: Central venous pressure.

\section{Competing interests}

The authors declare that they have no competing interests.

\section{Authors' contributions}

RR conceived and wrote the article. JRP conceived and edited the article and approved the final version. Both authors read and approved the final manuscript.

\section{Authors' information}

Rajkumar Rajendram BSC MBBS MRCP FRCA FFICM, Specialty registrar in Anaesthesia, Royal Free Hospital, London. John R Prowle MA MSc MD MRCP FFICM, Consultant in Renal Medicine and Intensive Care, The Royal London Hospital, London.

\section{Author details}

${ }^{1}$ Department of Anaesthesia, Royal Free Hospital, Hampstead, London NW3 2QG, UK. ${ }^{2}$ Adult Critical Care Unit, The Royal London Hospital, Barts Health NHS Trust, Whitechapel Road, London E1 1BB, UK.

\section{References}

1. Legrand M, Dupuis C, Simon C, Gayat E, Mateo J, Lukaszewicz AC, Payen D: Association between systemic hemodynamics and septic acute kidney injury in critically ill patients: a retrospective observational study. Crit Care 2013, 17:R278.

2. Dellinger RP, Levy MM, Rhodes A, Annane D, Gerlach H, Opal SM, Sevransky JE, Sprung CL, Douglas IS, Jaeschke R, Osborn TM, Nunnally ME, Townsend SR, Reinhart K, Kleinpell RM, Angus DC, Deutschman CS, Machado FR, Rubenfeld GD, Webb SA, Beale RJ, Vincent JL, Moreno R, Surviving Sepsis Campaign Guidelines Committee including the Pediatric Subgroup: Surviving sepsis campaign: international guidelines for management of severe sepsis and septic shock: 2012. Crit Care Med 2013, 41:580-637.

3. Gottschalk CW, Mylle M: Micropuncture study of pressures in proximal tubules and peritubular capillaries of the rat kidney and their relation to ureteral and renal venous pressures. Am J Physiol 1956, 185:430-439.

4. Mullens W, Abrahams Z, Francis GS, Sokos G, Taylor DO, Starling RC, Young JB, Tang WH: Importance of venous congestion for worsening of renal function in advanced decompensated heart failure. J Am Coll Cardiol 2009, 53:589-596.

5. Boyd JH, Forbes J, Nakada T, Walley KR, Russell JA: Fluid resuscitation in septic shock: a positive fluid balance and elevated central venous pressure are associated with increased mortality. Crit Care Med 2011, 39:259-265.

6. Prowle JR, Kirwan CJ, Bellomo R: Fluid management for the prevention and attenuation of acute kidney injury. Nat Rev Nephrol 2014, 10:37-47.

$10.1186 / \mathrm{cc} 13709$

Cite this article as: Rajendram and Prowle: Venous congestion: are we adding insult to kidney injury in sepsis?. Critical Care 2014, 18:104 